\title{
Systemic antibody response to Clostridium difficile in colonized patients with and without symptoms and matched controls
}

\section{Correspondence \\ Ian R. Poxton \\ i.r.poxton@ed.ac.uk}

Received 23 October 2007

Accepted 30 January 2008

\author{
Karla Sánchez-Hurtado, ${ }^{1}$ Maria Corretge, ${ }^{2}$ Esvet Mutlu, ${ }^{1}$ \\ Rowan Mcllhagger, ${ }^{2}$ John M. Starr ${ }^{2}$ and lan R. Poxton ${ }^{1}$ \\ ${ }^{1}$ Centre for Infectious Diseases, University of Edinburgh College of Medicine and Veterinary \\ Medicine, The Chancellor's Building, 49 Little France Crescent, Edinburgh EH16 4SB, UK \\ ${ }^{2}$ Geriatric Medicine Unit, University of Edinburgh College of Medicine and Veterinary Medicine, \\ Edinburgh EH16 4SB, UK
}

It has been proposed that patients who develop Clostridium difficile-associated disease (CDAD) do so because they are unable to mount an adequate immune response. Serum was collected from three groups of elderly in-patients: (i) cases $(n=21)$ of CDAD, being toxin A/B-positive; (ii) carriers ( $n=21$ ) asymptomatic for CDAD (no diarrhoea) but at least toxin or culture positive; and (iii) controls $(n=26)$ asymptomatic for CDAD and negative for both $C$. difficile toxin and culture. The age and gender of each group were compared, and the colonizing strains were ribotyped and toxinotyped. Serum antibodies ( $\lg G$ and $\lg M$ ) were measured by ELISA using different antigen preparations: EDTA extract (containing cell-surface proteins and carbohydrates), guanidine hydrochloride extract (surface-layer proteins), aqueous phenol-extracted lipocarbohydrate (LC); crude toxin (dialysis culture supernatant) and purified toxin A. LPS from Escherichia coli was used as a control antigen. Antibodies were also tested for toxin neutralization on tissue monolayers and for binding to EDTA-extracted antigens by Western blotting. IgG antibody measurements to cytomegalovirus (CMV) were included as an indicator of potential immunosenescence. Results showed that the patient groups were well matched by age and gender, and the colonizing strains were similar in cases and carriers, being predominantly ribotype 001 and toxinotype 0 . By ELISA, IgG levels to most of the antigens were highest in the cases and lowest in the controls, with the exception of antibodies to the LC, which were higher in the controls than the cases. Levels in the carriers tended to be of intermediate level or similar to the controls. For all antigens, the levels of IgM were not significantly different among cases, carriers and controls. Serum from all groups was able to neutralize the cytotoxic action of toxin on both Vero and Caco2 cells, and all to a similar extent. Western blots showed an overall higher level of IgG antibodies to the EDTA-extracted antigens in the cases. The results of the CMV ELISA showed that specific IgG was detected in more cases $(78 \%)$ than carriers and controls (both $65 \%$ ), but this difference in seropositivity was not significant. The conclusion is that, during symptomatic infection, patients respond to protein antigens of $\mathrm{C}$. difficile in a manner typical of a secondary antibody response, with no evidence that an inability to respond predisposes to the appearance of symptoms.

\section{INTRODUCTION}

Cases of Clostridium difficile-associated disease (CDAD) continue to increase with a seemingly concomitant higher proportion of patients with more-severe disease requiring surgery or contributing to death. In many parts of Europe and North America, this has coincided with the emergence

Abbreviations: AP, alkaline phosphatase; CDAD, Clostridium difficileassociated disease; CMV, cytomegalovirus; LC, lipocarbohydrate; SLP, surface-layer protein. of a hypervirulent strain, known as ribotype BI, NAP1 or 027 (Bartlett, 2006). Such strains have the potential to cause more-severe disease by producing higher levels of toxin (Warny et al., 2005).

However, there is the belief that the immune response of the host is crucial in determining the outcome of colonization with $C$. difficile and may be independent of the infecting strain. The ability of the host to produce specific antibodies against toxins and/or cellular antigens (Mulligan et al., 1993; Kyne et al., 2000) and to initiate the 
most appropriate cellular response (Johal et al., 2004) have been postulated as key factors to explain the variability in the response of the host to colonization with $C$. difficile by conferring protection against the negative effects of the bacterium. In particular, the inability of a patient to mount an adequate antibody response to the toxins (or other antigens) may be crucial for their predisposition to recurrent episodes of disease after an initial resolution of symptoms (Kyne et al., 2001). It is considered by some that the host response to non-toxin antigens is as important as that to toxins, by preventing adhesion or other pathogenic mechanisms (Drudy et al., 2004; Péchiné et al., 2007).

Most of the world's population has been infected at some point in their lives with cytomegalovirus (CMV). Once infected, the virus usually lies dormant until the immune system is weakened, and only causes problems in vulnerable groups such as babies, pregnant women or the immunocompromised, for example transplant patients, those on chemotherapy for malignancies and human immunodeficiency virus patients. In these groups, infection can severely affect organs including the eye, liver, gastrointestinal system and nervous system (Ogilvie, 2002). Recently, immunosenescence, a condition recognized in the elderly and linked to oligoclonal expansion mainly of $\mathrm{CD} 8{ }^{+} \mathrm{T}$ cells, has been linked to seropositivity to CMV (Pawelec et al., 2006). Infection with CMV at any age can bring about these changes in $\mathrm{T}$-cell subsets that are similar to age-related changes, with possible consequences for susceptibility to other infections (Looney et al., 1999). The CMV status of a patient might therefore be linked to susceptibility to $C$. difficile. CMV has also been reported as a cause of pseudomembranous colitis in cases of severely immunocompromised patients (such as AIDS, leukaemia and transplant patients), both on its own (Olofinlade \& Chiang, 2001; Cadena et al., 2007) and during co-infection with C. difficile (Ives \& Smith, 1996; Riva et al., 2005). Such a co-infection with $\mathrm{CMV}$ in patients carrying $C$. difficile might help to precipitate the symptoms associated with $\mathrm{CDAD}$, and therefore patients carrying both CMV and $C$. difficile might be at a higher risk of developing symptoms.

The main aim of this study was to explore the different abilities of patients to mount an antibody response to toxins and cell-associated antigens by comparing the outcome of colonization with $C$. difficile in terms of antibody responses in three groups of hospitalized elderly patients: (i) confirmed cases of CDAD, (ii) asymptomatic carriers of $C$. difficile, and (iii) asymptomatic controls who were negative for $C$. difficile. Secondary aims were to identify any differences among the patient groups in terms of gender or age, the strains infecting them and their CMV status.

\section{METHODS}

Bacterial strains. An example of the local epidemic ribotype 1, toxinotype 0 strain, MPRL 338a (McCoubrey, 2002), was chosen as the strain from which antigens were extracted, as many of the patients were likely to be colonized with this strain. Throughout the study, strains were maintained as spore suspensions in cooked meat broth at room temperature.

Patients and collection of specimens. Patients were over 65 years of age, in long-stay hospitalization and under antibiotic treatment. Those with dementia were not considered, as they could not consent for themselves. Blood and stool samples were collected in accordance with the Local Research Ethics Committee consent from every major hospital in Edinburgh, with the majority - cases, carriers and controls - from the Royal Victoria Hospital, the main geriatric assessment and rehabilitation hospital for the north of Edinburgh. Blood was allowed to clot overnight at $4{ }^{\circ} \mathrm{C}$, and serum was separated by centrifugation and stored at $-20{ }^{\circ} \mathrm{C}$.

Patients were arranged retrospectively into three groups: (i) cases, diagnosed $\mathrm{CDAD}$ cases (toxin $\mathrm{A} / \mathrm{B}$ positive), symptomatically colonized with $C$. difficile; (ii) carriers, asymptomatic for CDAD (no diarrhoea), but at least toxin A/B positive or culture positive; and (iii) controls, asymptomatic for $\mathrm{CDAD}$, and both $C$. difficile toxin (A/B) negative and culture negative. The cases were selected by the requirement that they were toxin positive in stools to avoid misdiagnosis of the symptoms. If the patient had diarrhoea or was suspected to have CDAD but was toxin negative in stool samples, they were not considered for the study, independent of their colonization status. It was not possible to interrogate patients or see their notes to see whether they had experienced CDAD or diarrhoea previously.

The timings of collection of blood and stool samples from the patients were as close together as possible, ideally within $24 \mathrm{~h}$. However, it should be noted that for all patients, and in particular for the carriers and controls, it was impossible to know their carriage status at the precise time of sampling and, if they were carrying C. difficile, for how long they had been colonized.

Culture of stool samples and identification of $\boldsymbol{C}$. difficile. Stools were cultured directly on Brazier's cefoxitin cycloserine egg yolk (CCEY) agar (Oxoid) and incubated at $37{ }^{\circ} \mathrm{C}$ under anaerobic conditions $\left(10 \% \mathrm{H}_{2}, 10 \% \mathrm{CO}_{2}, 80 \% \mathrm{~N}_{2}\right)$ for $24-48 \mathrm{~h}$. Positive results were seen within that period. If negative, the plates were incubated for a further $48 \mathrm{~h}$ to confirm the negative results. Preliminary identification of $C$. difficile was carried out by colony morphology, a characteristic smell, visualization of motility by phasecontrast microscopy and chartreuse fluorescence under long-wave UV light (Wood's lamp). Further identification included a Gram film and toxin assay.

Toxin assays. Toxin was measured either in fresh stools (less than $24 \mathrm{~h}$ after collection) or following isolation of pure cultures of $C$. difficile and growth at $37{ }^{\circ} \mathrm{C}$ under anaerobic conditions $\left(10 \% \mathrm{H}_{2}\right.$, $10 \% \mathrm{CO}_{2}, 80 \% \mathrm{~N}_{2}$ ) for 5-6 days in proteose peptone yeast extract medium (Deacon et al., 1978) using a commercially available kit (C. difficile toxin $\mathrm{A}+\mathrm{B}$; Techlab) following the instructions of the manufacturer.

Ribotyping. PCR ribotyping was carried out following the method described by O'Neill et al. (1996). Specific oligonucleotide primers complementary to the $3^{\prime}$ end of the $16 \mathrm{~S}$ rRNA gene $\left(5^{\prime}\right.$ CTGGGGTGAAGTCGTAACAAGG-3', nt 1445-1466) and the $5^{\prime}$ end of the $23 \mathrm{~S}$ rRNA gene ( $5^{\prime}$-GCGCCCTTTGTAGCTTGACC-3', nt 1-20) were used to amplify the variable-length intergenic spacer region. Primers were obtained from MWG.

The total volume of the PCR was $100 \mu$ containing PCR buffer [20 mM Tris/HCl (pH 9.0), $50 \mathrm{mM} \mathrm{KCl],} 2.25 \mathrm{mM} \mathrm{MgCl}, 2 \mathrm{U}$ Taq polymerase (all from Invitrogen), $200 \mu \mathrm{M}$ each dNTP (Amersham Pharmacia Biotech), 50 pmol each primer and $10 \mu$ template DNA. Initial denaturation was carried out at $94{ }^{\circ} \mathrm{C}$ for $3 \mathrm{~min}$. The mixtures 
were then subjected to 35 cycles of denaturation at $94{ }^{\circ} \mathrm{C}$ for $1 \mathrm{~min}$, annealing at $55{ }^{\circ} \mathrm{C}$ for $1 \mathrm{~min}$ and extension at $72{ }^{\circ} \mathrm{C}$ for $2 \mathrm{~min}$. A final elongation step was included at $72{ }^{\circ} \mathrm{C}$ for $5 \mathrm{~min}$.

The amplification products were concentrated to a final volume of $12-15 \mu \mathrm{l}$ by heating at $75{ }^{\circ} \mathrm{C}$ for $100 \mathrm{~min}$, and run on $3 \%$ MetaPhor agarose gels (ABgene) at $80 \mathrm{~V}$ for $2.5 \mathrm{~h}$. A $100 \mathrm{bp}$ DNA ladder (ABgene) was used as a size marker.

Patterns were identified by comparison with those already included in the laboratory database. The concentrated PCR products of those that were different were sent to the Anaerobe Reference Unit in Cardiff (UK) to be identified.

Toxinotyping. Toxinotyping was carried out following the method described by Rupnik et al. $(1997,1998)$. The first $3 \mathrm{~kb}$ of the toxin B gene $(t c d B$, PCR fragment $\mathrm{B} 1)$ and the $3 \mathrm{~kb}$ repetitive region of the toxin A gene ( $t c d A$; PCR fragment A3) were detected and characterized by RFLP. Primers were obtained from MWG. The primers used were: A3C (5'-TATTGATAGCACCTGATTTATATACAAG- $\left.3^{\prime}\right)$ and A4N (5' ${ }^{\prime}$ TTATCAAACATATATTTTAGCCATATATC-3') for $t c d A$ (3100 bp amplicon); and B1C (5'-AGAAAATTTTATGAGTTTAGTTAATAGAAA-3') and B2N (5'-CAGATAATGTAGGAAGTAAGTCTATAG-3') for $t c d B$ (3100 bp amplicon).

PCRs were performed in a final volume of $50 \mu$ containing PCR buffer [20 mM Tris/HCl (pH 9.0, $50 \mathrm{mM} \mathrm{KCl}$ ], $3 \mathrm{mM} \mathrm{MgCl}_{2}, 1 \mathrm{U}$ Taq polymerase (all from Invitrogen), $200 \mu \mathrm{M}$ each dNTP (Amersham Pharmacia Biotech), $15 \mathrm{pmol}$ each primer and $5 \mu \mathrm{l}$ template DNA. For amplification of A3 fragments, $1 \% \mathrm{~W}-1$ detergent (Invitrogen), tetramethylammonium chloride (final concentration $10^{-4} \mathrm{M}$; Sigma) and BSA (final concentration $0.1 \mathrm{mg} \mathrm{ml} \mathrm{m}^{-1}$; Promega) were also added. After initial denaturation at $93{ }^{\circ} \mathrm{C}$ for 3 min, $\mathrm{B} 1$ products were amplified for 30 cycles and $\mathrm{A} 3$ products for 35 cycles of annealing and extension at $47^{\circ} \mathrm{C}$ for $8 \mathrm{~min}$, and denaturation at $93^{\circ}$ for $4 \mathrm{~s}$. Final extension was performed at $47^{\circ} \mathrm{C}$ for $10 \mathrm{~min}$.

Amplified fragments were subjected to restriction enzyme digestions using AccI and HincII for B1, and EcoRI for A3. Restriction enzymes were obtained from New England BioLabs. Incubation with $1 \mu \mathrm{l}$ (in a final volume of $20 \mu \mathrm{l}$ ) of the enzymes was carried out at $37^{\circ} \mathrm{C}$ for $2 \mathrm{~h}$. In the restriction of B1 with HincII, $10 \%$ BSA (Promega) was also added. After electrophoresis of the digestion products in $1 \%$ agarose gels, toxinotypes of all tested isolates were identified as described by Rupnik et al. (1997, 1998).

Production of crude toxin by dialysis culture. Crude toxin was produced as described by Sánchez-Hurtado \& Poxton (2008) (this issue). The supernatant, which contained toxins A and B together with other extracellular products, including surface-layer proteins (SLPs) (shown by SDS-PAGE), but none of the culture medium components, was filter-sterilized and stored at $4{ }^{\circ} \mathrm{C}$.

Purification of toxin A. Toxin A was purified as described by Sánchez-Hurtado \& Poxton (2008).

EDTA extraction of surface proteins and extraction of SLPs. EDTA extraction of surface proteins and extraction of SLPs were carried out as described by Sánchez-Hurtado \& Poxton (2008).

Extraction of surface lipocarbohydrate (LC). This method was based on those described previously by Poxton \& Cartmill (1982) and Sharp \& Poxton (1986), and was carried out as described by SánchezHurtado \& Poxton (2008). LPS from an Escherichia coli R mutant was taken from our laboratory stocks. It had been prepared by petroleum/ chloroform/phenol extraction and complexed with polymyxin B, and was prepared and used in ELISA as described by Gibbs et al. (2004).
ELISA. PolySorp plates (Nunc) were coated with $100 \mu$ l of the appropriate concentration of the chosen antigen in antigen buffer [0.05 M sodium carbonate buffer ( $\mathrm{pH}$ 9.6), $0.02 \%$ sodium azide] and incubated overnight in darkness at room temperature. Plates were washed in PBS (pH 7.4; Oxoid) four times and blocked with $100 \mu \mathrm{l}$ TG buffer $[0.05 \mathrm{M}$ phosphate buffer ( $\mathrm{pH} 7.4$ ) containing $2 \%$ teleostean gelatin and $0.1 \%$ Tween 20] for $90 \mathrm{~min}$. After four washes in PBS, the plates were incubated for $90 \mathrm{~min}$ with $100 \mu \mathrm{l}$ of the chosen serum diluted $1: 10$ in antiserum buffer $[0.05 \mathrm{M}$ sodium phosphate buffer ( $\mathrm{pH} 7.4$ ) containing $0.085 \% \mathrm{NaCl}, 0.05 \%$ Tween 20 and $0.02 \%$ sodium azide] and then washed four times as above. The plates were then incubated with a 1:10 000 dilution of antihuman (IgG or IgM) alkaline phosphatase (AP) conjugate (Sigma) in antiserum buffer for $90 \mathrm{~min}$ and developed with AP substrate (Sigma tablets) in AP substrate buffer $[0.05 \mathrm{M}$ sodium carbonate ( $\mathrm{pH} 9.8$ ) containing $1 \mathrm{mM} \mathrm{MgCl}$ ] . The $A_{405}$ was measured at $15 \mathrm{~min}$ intervals for $1 \mathrm{~h}$ in an ELISA plate reader (Anthos Reader 2001) with the reference filter at $620 \mathrm{~nm}$. All assays were carried out at least twice.

Three different negative controls (buffer only, antigen and no serum, serum and no antigen) were included. Background levels were in the range of $0.03-0.05$ absorbance units $(405 / 620 \mathrm{~nm})$. A standard positive control [pooled serum from young (under 65 years old) healthy, non-hospitalized volunteers] was included on each plate to ensure reproducibility of the assay, and each set of assays was carried out on the same one or two plates from the same batch.

Western blotting. Surface proteins were extracted with EDTA as described above. Samples were mixed in equal volumes of doublestrength sample buffer, heated at $100{ }^{\circ} \mathrm{C}$ for $3-5 \mathrm{~min}$ and then analysed by $10 \%$ bisacrylamide/Tris PAGE (Invitrogen) following the manufacturer's instructions and using MOPS SDS running buffer supplied by the manufacturer. Gels were run at $150 \mathrm{~V}$ until the dye front reached the bottom of the gel $(\sim 30-45 \mathrm{~min})$. The separated antigens were transferred to a nitrocellulose membrane at $150 \mathrm{~V}$ for 100 min at $4{ }^{\circ} \mathrm{C}$. The membrane was then blocked with $8 \%$ skimmed milk powder (Marvel) in PBS overnight at $4{ }^{\circ} \mathrm{C}$. After three $10 \mathrm{~min}$ washes in PBS at room temperature, the membrane was incubated with rocking in a $1: 1000$ dilution of human serum in $1 \%$ skimmed milk powder/PBS $/ 0.05 \%$ Tween 20 for $3 \mathrm{~h}$ at room temperature. The membrane was then washed three times $(10 \mathrm{~min}$ each, room temperature) with $1 \%$ skimmed milk powder/PBS/0.05\% Tween 20 , followed by incubation with secondary antibody (anti-human IgG horseradish peroxidase-conjugate) at a $1: 10000$ dilution in $1 \%$ skimmed milk powder/PBS/0.05\% Tween 20 for $90 \mathrm{~min}$. After three 10 min washes in $1 \%$ skimmed milk powder/PBS/0.05\% Tween 20 at room temperature, the membrane was incubated with enhanced chemiluminescence solution (containing $250 \mathrm{mM}$ luminol and $90 \mathrm{mM}$ p-coumaric acid in DMSO) for 5-10 min and analysed by autoradiography using Hyperfilm ECL (Amersham Biosciences) and an X-Ray film developer (Protec).

Cell culture. The Vero cell line is a well established cell line originally obtained from kidney epithelium of the African green monkey, and has been used extensively for testing $C$. difficile cytotoxicity. The $\mathrm{Caco} 2$ lineage was obtained from human colonic tumour and is used as a model for the human intestine. This lineage spontaneously differentiates after reaching confluency. Vero cells and Caco2 cells were used from our frozen stocks and grown as described by SánchezHurtado \& Poxton (2008). A $10 \%$ inoculum $\left(10^{6}\right.$ cells $\left.\mathrm{ml}^{-1}\right)$ was used to inoculate new flasks.

Although it might have been preferable to use the Caco 2 cells after they had differentiated, it was difficult to ensure that every layer of cells was exposed to the same concentration of toxin. Therefore for both lines the cells were used when they had just reached confluency. 
Neutralization of cytotoxic effect with serum. The wells of microtitre plates were seeded with $100 \mu \mathrm{l}$ cells (Vero or Caco2) and incubated for $24 \mathrm{~h}$ until they reached confluency. Non-purified toxin was added to the wells $\left(10 \mu \mathrm{l} 150 \mu \mathrm{g}\right.$ toxin $\mathrm{ml}^{-1}$ solution) and incubated for 3 days with and without the addition of equal volumes $(10 \mu \mathrm{l})$ of pooled serum from each of the groups of patients or $10 \mu \mathrm{l}$ medium in the case of blanks. At the end of the incubation period, an MTT assay was used to measure cell viability, as described by Sánchez-Hurtado \& Poxton (2008).

CMV IgG ELISA. A commercially available ELISA diagnostic kit for CMV (IBL Hamburg) was used as specified by the manufacturer.

Statistics. All tests were performed with the GraphPad Prism 4 package. Data were checked for normality and then compared with each other. If the distribution of the values was Gaussian, an unpaired $t$-test was performed. If the distribution was not normal, a MannWhitney test was used.

\section{RESULTS AND DISCUSSION}

\section{Patients}

Initially, 69 patients consented to take part and had blood samples taken. Of these, 21 were diagnosed as cases of CDAD by testing positive for toxin $\mathrm{A}+\mathrm{B}$. One patient had CDAD-like symptoms but was toxin $\mathrm{A}+\mathrm{B}$ negative and so was discarded from the study. The remaining 47 were asymptomatic for CDAD (no diarrhoea). However, following stool culture, 21 were found to carry the bacterium (carriers) and 26 were CDAD and C. difficile negative (controls). Stool samples were obtained from all asymptomatic patients within the $24 \mathrm{~h}$ prior to blood sampling. Of the 21 symptomatic patients, stools were not obtained for culture from 3 of them, but they had already tested positive for toxins $A+B$ in the routine diagnostic laboratory tests. All of the stool samples were tested for toxins $\mathrm{A}+\mathrm{B}$ as described above and cultured on CCEY agar. Thus, the final 68 patients investigated consisted of 21 cases, 21 asymptomatic carriers and 26 controls.

Of the 18 cases from whom a stool sample was available, 13 produced positive cultures of $C$. difficile. Of the five culture-negative stools, three had been frozen for several days before culturing and two were from patients being treated with metronidazole at the time of sampling.

All of the patients included in the study $(n=68)$ were elderly with an age range from 61 to 95 years, with just one patient under 66. This patient was accepted for the study because she had a degenerative condition that made her biologically older than her chronological age and she was hospitalized in a geriatric unit. The mean age of the group was 81.9 years and the gender ratio was $2: 1$ female: male (44 females, 22 males, 2 not recorded). Among the cases, this ratio decreased to $1.7: 1$ female:male (12 females, 7 males, 2 not recorded), the carriers were 2:1 (14 females, 7 males) and controls had a slightly higher proportion of females, 2.3: 1 (18 females, 8 males). Overall, the gender ratio was not considered significantly different among the groups. The mean age of the subgroups was 82.9 years for cases, 82.8 for carriers and 80.5 for controls. Although the mean age of the control group was 2 years younger than the cases and controls, these differences were not significant.

\section{Strains of C. difficile isolated}

The isolates from cases and carriers were characterized to see whether disease could be explained by the strain with which the host was colonized. From the culture-positive stool samples, 32 isolates (13 cases and 19 carriers) were selected for genotyping by PCR ribotyping and toxinotyping, as well as being tested for the ability to produce toxin in vitro. The isolates were predominantly ribotype 001 $(n=23,72 \%)$, followed by ribotype $106(n=4,12.5 \%)$, with single examples of ribotypes $010,023,046,070$ and 139. Most were toxinotype $0(n=29,91 \%)$, with one each of toxinotypes I and IV, and one non-toxigenic isolate. These reflect the types of strain isolated previously from patients in south-east Scotland, where Mutlu et al. (2007), upon investigating 149 isolates, found that $75.8 \%$ were ribotype $001,8.1 \%$ were ribotype 106 and $96.6 \%$ were toxinotype 0 . The hypervirulent strain ribotype 027 was not found in this population.

Symptomatic patients all produced toxin-positive stools by definition, and the isolates subsequently obtained from them all produced toxin in vitro. Of the asymptomatic patients investigated by culture, 19 were culture positive. Of the subsequent cultures, 18 produced toxin when incubated in vitro. The one that did not produce toxin after 1 week of incubation was confirmed as a non-toxigenic strain belonging to ribotype 010 and was non-toxinotypable as described above.

Of the common ribotypes, 001 was found in 9 cases and 14 carriers, and 106 in 1 case and 3 carriers, both reflecting the proportion of cases and carriers. Similarly, the 29 toxinotype 0 strains were found in 11 cases and 18 carriers, with the 2 uncommon toxinotypes both being in cases and the non-toxin-producing ribotype 010 in a carrier.

\section{Antibody response to toxin and cell-surface antigens}

Serum levels of IgG and IgM antibodies against crude and pure toxin A, EDTA-extracted surface antigens, SLPs and the LC of $C$. difficile, as well as the core of E. coli LPS, were measured by ELISA. The results are summarized in Fig. 1(a) for IgG and Fig. 1(b) for IgM. Overall, for most of the antigens, both IgG and IgM levels were largely similar among the three groups of patients, with a tendency for highest levels in the cases and lowest in the controls.

In Fig. 1(a), the IgG antibody levels against non-purified toxin were highest in the cases. When the means were compared, there was a significant difference between the cases and controls $(P=0.042)$, but not between cases and carriers $(P=0.138)$. However, when antibodies against 


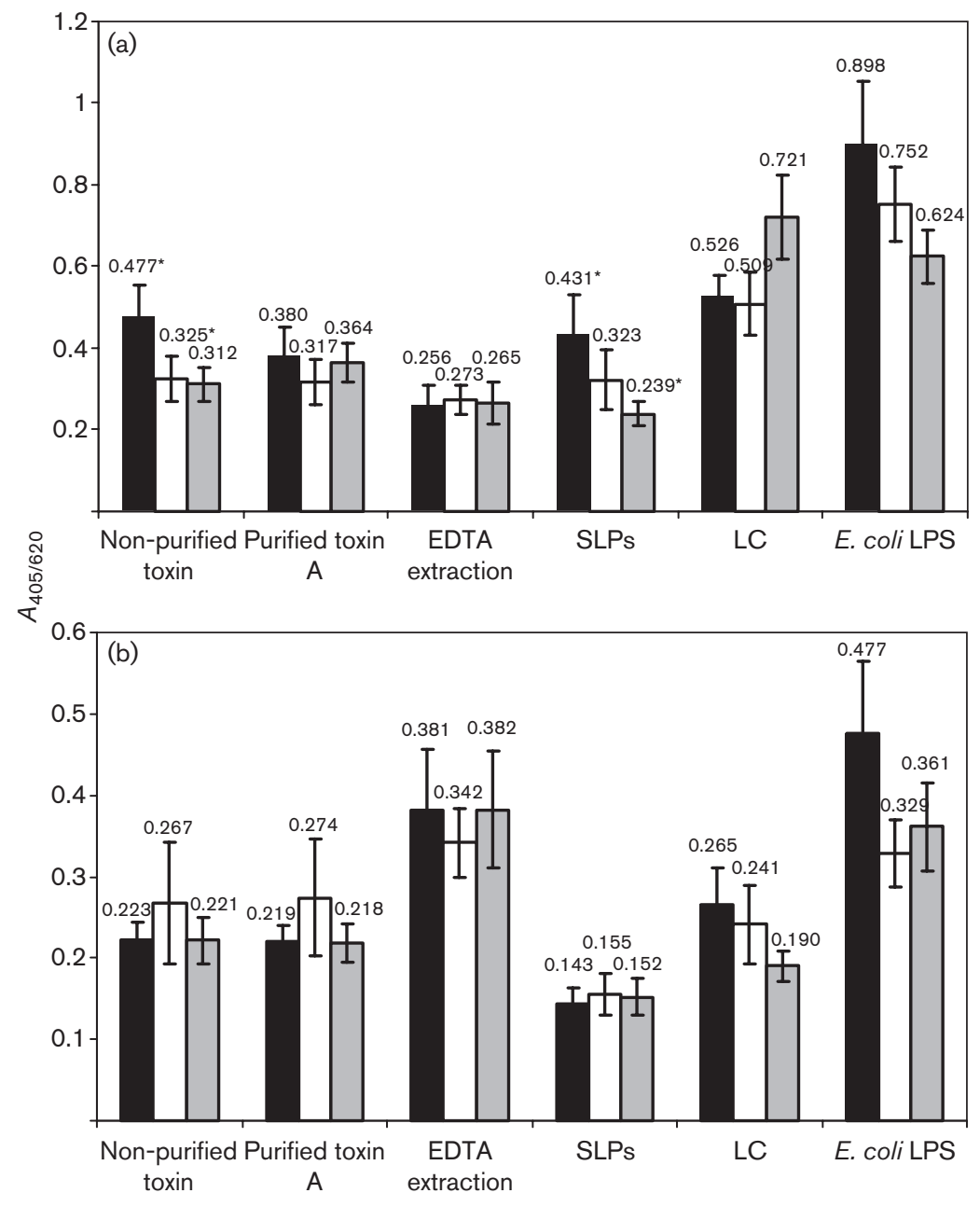

Fig. 1. Antibody responses to antigens of $C$. difficile and E. coli LPS analysed by ELISA for IgG (a) and IgM (b). Results are shown for cases ( $n=21$, black bars), carriers $(n=21$; white bars) and controls ( $n=26$; grey bars), and are given as mean absorbance values \pm SEM. ${ }^{*}, P<0.05$.

purified toxin A were measured, no differences were found among the groups.

The IgG antibody levels against the EDTA extract, which contains surface proteins and carbohydrates, were the same for the three groups $(P>0.750)$. However, when the antibody levels against the guanidine hydrochloride extraction (which contains the two SLPs) of the same standard strain were analysed, differences were found. These were similar to the non-purified toxin, where levels were highest in the cases. Means were analysed statistically and again differences were significant between cases and controls $(P=0.042)$, but not between cases and carriers $(P=0.373)$. The levels of antibodies against the surface LC of $C$. difficile were highest in the control group, but this difference was not statistically significant. No difference between the cases and controls was seen.

The results for IgM antibodies (Fig. 1b) were similar to the IgG levels, but no statistically different levels were measurable among any of the groups. The IgM levels against the surface proteins, both EDTA (surface proteins and carbohydrates) and guanidine hydrochloride (SLPs) extractions of a standard strain, were equal among all three groups. This was similar for the surface LC of C. difficile, where no significant differences were found.

The cases had the highest levels of IgG antibodies against the core of E. coli LPS, followed by the carriers and then the controls (Fig. 1a). For IgM (Fig. 1b), the highest levels were again in the cases, but the lowest levels were in the carriers. However, none of these differences were statistically significant.

Antibodies against the core of E. coli LPS were measured as controls with a view to investigating whether the differences among the groups were specific to C. difficile or were due to the general state of the immune system. The core oligosaccharide of $E$. coli LPS is an immunogenic antigen to which everyone is exposed, and antibodies - both IgG and IgM - can be detected in everyone (Poxton, 1995). The kinetics of circulating anti-LPS core antibodies have been proposed to be a good indicator of systemic exposure to LPS/endotoxin during sepsis (BennettGuerrero et al., 1997). If there has been increased LPS exposure to the systemic immune system during damage to the affected gut in the cases, then it would be expected that the antibody levels might be boosted. In contrast, if the 
patients were endotoxaemic/septic, which is not usual in CDAD patients, then the levels of anti-LPS antibodies would be expected to fall.

The functionality of the antibodies in the sera was measured by neutralization of toxin-induced cytotoxicity in Vero and Caco2 cells, and the results are shown in Fig. 2. It can be seen that the sera from each of the three groups (cases, carriers and controls) neutralized the toxin when compared with the toxin-only control $(P<0.0001$, asterisk not shown on figure). However, there were no significant differences among the sera from the three different groups.

The results of Western blotting on the EDTA-extracted antigens indicated that the serum pooled from cases gave a stronger signal and reacted with more bands than the sera from carriers and controls. There was a particularly strong reaction to two bands of approximately 50 and $35 \mathrm{kDa}$, which correspond to the SLPs, and a third, smaller band of just under $15 \mathrm{kDa}$ (results not shown). Those patients symptomatically colonized by $C$. difficile had a higher level of IgG against several surface proteins compared with those not colonized or colonized but without symptoms.

In summary, and contrary to our initial hypothesis, cases (patients symptomatically colonized with $C$. difficile) did not have lower levels of antibodies to $C$. difficile compared with carriers when measured by three different methods: ELISA, neutralization of cytotoxicity and Western blotting against surface proteins, and their ability to respond to specific $C$. difficile antigens and to LPS did not appear to be compromised; perhaps, in retrospect, this is not surprising. The results of this study agree with other studies that did not find significant differences in the levels of systemic antibodies between CDAD cases and controls (Drudy et al., 2004; Johal et al., 2004). Péchiné et al. (2005) showed that CDAD patients had lower levels of specific antibodies to different cell-wall antigens than women in maternity wards and children.
In all of the patients tested, including the controls, and in large numbers of healthy individuals who have not been reported on in this study, there is a detectable level of preexisting antibodies to $C$. difficile. These antibodies will be produced throughout life and perhaps initially stimulated in infancy by constant environmental exposure to $C$. difficile itself and perhaps to other clostridia, such as Clostridium sordellii, which possess cross-reacting antigens. It seems likely that antibody levels begin to be boosted following colonization and that this is further enhanced by the disease itself, as is typical of a secondary antibody response.

Kyne et al. (2000) found that the symptomatic patients had lower levels of IgG against toxin A and of IgM against nontoxin antigens, but they also found that the symptomatic patients had on average more-severe diseases and that a higher percentage was admitted to intensive care units. This information was not available for our study. However, it is possible that the cases had more-severe underlying diseases than the carriers, and that perhaps it is this that is compromising a protective immune response against $C$. difficile before CDAD develops. The healthier carriers may be able to mount a protective response prior to the development of CDAD.

Another possibility is that the key feature is the point at which antibodies are produced, rather than on the ability per se to produce the antibodies or the levels of antibodies produced. If individuals are exposed for long enough to $C$. difficile before their gut microbiota is severely affected, they might be able to produce specific antibodies that could be protective, even if the microbiota is affected afterwards. The level of antibodies before infection with $C$. difficile might also be crucially important in stopping symptoms developing. Another point to note is that, for ethical reasons, patients that were medically very unwell, or indeed terminally ill with CDAD, were not approached to join the

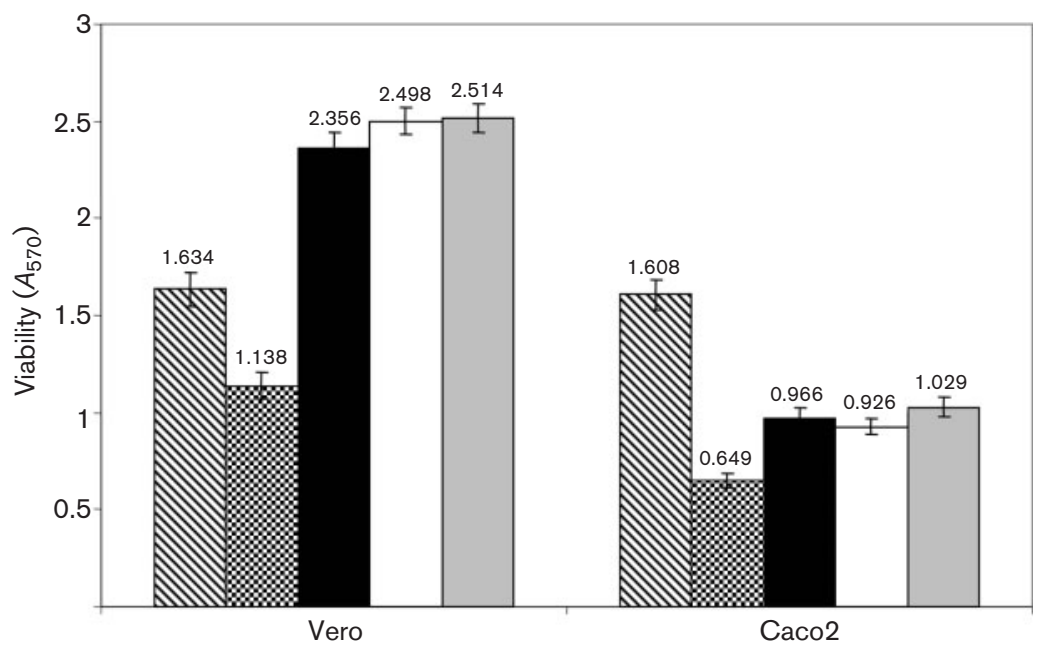

Fig. 2. Neutralization of toxin cytotoxicity by addition of pooled serum from each of the patient groups. Results are shown as mean $A_{570}$ values \pm SEM for the 21 cases, 21 carriers and 26 controls. Each test was carried out in duplicate. Hatched bars, unchallenged cells; spotted bars, cells + toxin; black bars, cells +toxin + sera from cases; white bars, cells + toxin + sera from carriers; grey bars, cells + toxin + sera from controls. 
study. It is therefore possible that the immune response of these individuals would have differed from that found in our cases.

However, the fact that the antibody levels were only a little higher in the cases might indicate that, even if they are not significantly immunocompromised, their immune system could be inefficient due to age (immunosenescence) and/or other diseases and infections. The mean age of the patients of our study was 82 years and only patients aged 65 or over were recruited. In the study by Kyne et al. (2000), patients of all age groups were included, with $23 \%$ being under 65 years, with a resultant mean age of 74 .

The significantly higher levels of IgG against non-purified toxin and against SLPs is an indication that, at least at one point, cases were able to respond to $C$. difficile. Note that the non-purified toxin contained SLPs, and this may be the reason why there were higher levels of antibody. Measuring IgM levels is probably not very useful, as all of the subjects were probably already producing antibodies and infection would only produce a boosting of a secondary response, with a primary response being unlikely.

\section{Antibodies to CMV}

The levels of IgG against CMV were measured using a commercial ELISA kit. Tests were performed in duplicate on 64 of the patients ( 18 cases, 20 carriers and 26 controls). The results are summarized in Fig. 3. Of the 64 patients, 44 (69\%) tested positive for CMV antibodies: 14 were cases, 13 were carriers and 17 were controls. One, a carrier, was in the grey area between positive and negative, and the remaining 19 (4 cases, 6 carriers and 9 controls) were negative. These levels are above the normally expected levels of $40-60 \%$ in 'mid-adult life', but this can increase to over $90 \%$ in those with 'multiple intimate exposures'

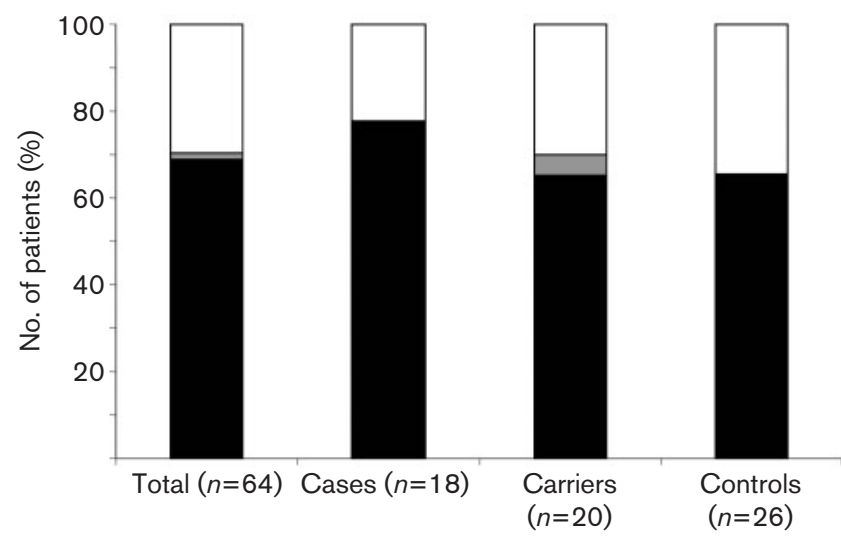

Fig. 3. Proportions of patients giving positive and negative results for anti-CMV IgG by ELISA. The 'grey zone' indicates results that were between positive and negative levels. Black, CMV infection; grey, 'grey zone'; white, no infection.
(Ogilvie, 2002). A higher proportion of the cases of CDAD tested positive, with a $13 \%$ difference between cases $(78 \%)$ and both carriers and controls (both $65 \%$ ). If CMV had reactivated in the patients, it might suggest that cases are in fact more ill - with regard to other illnesses for which they are in hospital - than carriers or controls. More work is needed to support this hypothesis, but it is consistent with the findings of Kyne et al. (2000) who analysed the severity of the primary disease in the patients of their study. $C$. difficile is an opportunistic pathogen, and the inadequate immune response that other authors have found may be related to, but not necessarily causing, CDAD. Co-infection of $C$. difficile and CMV or other opportunistic pathogens might be an area worth exploring further.

In conclusion, the patients with CDAD appeared to be able to mount an immune response to $C$. difficile antigens that was better or at least equivalent to the response in asymptomatic carriers of the bacterium. The basis of their predisposition to develop symptoms is not simply an inability to respond; it might well be due to the timing and specificity of the response - both in the gastrointestinal tract (mucosal response) and in the systemic circulation. Future areas of study should include longitudinal studies of both systemic and mucosal responses.

\section{ACKNOWLEDGEMENTS}

This study was supported by a grant (CZG/1/159) from the Chief Scientist Office, Scottish Government Health Department, and K. S.-H. was supported by a grant from Fundación Mutua Madrileña. We thank Jon Brazier and colleagues at the Anaerobe Reference Unit, Cardiff, UK, for help in identifying some of the ribotypes.

\section{REFERENCES}

Bartlett, J. G. (2006). Narrative review: the new epidemic of Clostridium difficile-associated enteric disease. Ann Intern Med 145, 758-764.

Bennett-Guerrero, E., Ayuso, L., Hamilton-Davies, C., White, W. D., Barclay, G. R., Smith, P. K., King, S. A., Muhlbaier, L. H., Newman, M. F. \& Mythen, M. G. (1997). Relationship of preoperative anti-endotoxin core antibodies and adverse outcomes following cardiac surgery. JAMA 277, 646-650.

Cadena, J., Owens, A., Blankenship, J. \& Chung, R. (2007). Cytomegalovirus pseudomembranous colitis in an immunocompetent patient: case report and review of the literature. Infect Dis Clin Pract 15, 213-216.

Deacon, A. G., Duerden, B. I. \& Holbrook, W. P. (1978). Gas-liquid chromatographic analysis of metabolic products in the identification of Bacteroidaceae of clinical interest. J Med Microbiol 11, 81-99.

Drudy, D., Calabi, E., Kyne, L., Sougioultzis, S., Kelly, E., Fairweather, N. \& Kelly, C.P. (2004). Human antibody response to surface layer proteins in Clostridium difficile infection. FEMS Immunol Med Microbiol 41, 237-242.

Gibbs, R. J., Stewart, J. \& Poxton, I. R. (2004). The distribution of, and antibody response to, the core lipopolysaccharide region of Escherichia coli isolated from the faeces of healthy humans and cattle. J Med Microbiol 53, 959-964. 
Ives, D. V. \& Smith, R. N. (1996). Case 17-1996. A 48-year-old man with the acquired immunodeficiency syndrome, abdominal pain, and bloody diarrhea. N Engl J Med 334, 1461-1468.

Johal, S. S., Lambert, C. P., Hammond, J., James, P. D., Borriello, S. P. \& Mahida, Y. R. (2004). Colonic IgA producing cells and macrophages are reduced in recurrent and non-recurrent Clostridium difficile associated diarrhoea. J Clin Pathol 57, 973-979.

Kamiya, S., Reed, P. J. \& Borriello, S. P. (1989). Purification and characterisation of Clostridium difficile toxin A by bovine thyroglobulin affinity chromatography and dissociation in denaturing conditions with or without reduction. J Med Microbiol 30, 69-77.

Krivan, H. C. \& Wilkins, T. D. (1987). Purification of Clostridium difficile toxin A by affinity chromatography on immobilized thyroglobulin. Infect Immun 55, 1873-1877.

Kyne, L., Warny, M., Qamar, A. \& Kelly, C. P. (2000). Asymptomatic carriage of Clostridium difficile and serum levels of IgG antibody against toxin A. N Engl J Med 342, 390-397.

Kyne, L., Warny, M., Qamar, A. \& Kelly, C. P. (2001). Association between antibody response to toxin $\mathrm{A}$ and protection against recurrent Clostridium difficile diarrhoea. Lancet 357, 189-193.

Looney, R. J., Falsey, A., Campbell, D., Torres, A., Kolassa, J., Brower, C., McCann, R., Menegus, M., McCormick, K. \& other authors (1999). Role of cytomegalovirus in the $\mathrm{T}$ cell changes seen in elderly individuals. Clin Immunol 90, 213-219.

McCoubrey, J. (2002). The epidemiology of Clostridium difficile in a geriatric unit. PhD thesis, University of Edinburgh, UK.

Mulligan, M. E., Miller, S. D., McFarland, L. V., Fung, H. C. \& Kwok, R. Y. (1993). Elevated levels of serum immunoglobulins in asymptomatic carriers of Clostridium difficile. Clin Infect Dis 16 (Suppl. 4), S239-S244.

Mutlu, E., Wroe, A. J., Sánchez-Hurtado, K., Brazier, J. S. \& Poxton, I. R. (2007). Molecular characterization and antimicrobial susceptibility patterns of Clostridium difficile strains isolated from hospitals in south-east Scotland. J Med Microbiol 56, 921-929.

O’Neill, G. L., Ogunsola, F. T., Brazier, J. S. \& Duerden, B. I. (1996). Modification of a PCR ribotyping method for application as a routine typing scheme for Clostridium difficile. Anaerobe 2, 205-209.

Ogilvie, M. M. (2002). Herpes viruses. In Medical Microbiology. A Guide to Microbial Infections: Pathogenesis, Immunity, Laboratory Diagnosis and Control, 16th edn, pp. 399-420. Edited by D. Greenwood, R. C. B. Slack \& J. F. Peutherer. Edinburgh: Churchill Livingstone.

Olofinlade, O. \& Chiang, C. (2001). Cytomegalovirus infection as a cause of pseudomembrane colitis: a report of four cases. J Clin Gastroenterol 32, 82-84.
Pawelec, G., Koch, S., Franceschi, C. \& Wikby, A. (2006). Human immunosenescence: does it have an infectious component? Ann N Y Acad Sci 1067, 56-65.

Péchiné, S., Janoir, C. \& Collignon, A. (2005). Variability of Clostridium difficile surface proteins and specific serum antibody response in patients with Clostridium difficile-associated disease. J Clin Microbiol 43, 5018-5025.

Péchiné, S., Janoir, C., Boureau, H., Gleizes, A., Tsapis, N., Hoys, S., Fattal, E. \& Collignon, A. (2007). Diminished intestinal colonization by Clostridium difficile and immune response in mice after mucosal immunization with surface proteins of Clostridium difficile. Vaccine 25, 3946-3954.

Poxton, I. R. (1995). Antibodies to lipopolysaccharide. J Immunol Methods 186, 1-15.

Poxton, I. R. \& Byrne, M. D. (1981). Immunological analysis of Clostridium difficile and related species. J Gen Microbiol 122, 41-46.

Poxton, I. R. \& Cartmill, T. D. I. (1982). Immunochemistry of the cellsurface carbohydrate antigens of Clostridium difficile. J Gen Microbiol 128, 1365-1370.

Riva, G., Luppi, M., Potenzar, L., Morselli, M., Ferrari, A., Saviola, A., Volzone, F., Imovilli, A., Merighi, A. \& other authors (2005). Cytomegalovirus and Clostridium difficile co-infection in severe ulcero-hemorrhagic colitis during induction chemotherapy for acute lymphoblastic leukemia. Haematologica 90, ECR01.

Rupnik, M., Braun, V., Soehn, F., Janc, M., Hofstetter, M., Laufenberg-Feldmann, R. \& von Eichel-Streiber, C. (1997). Characterization of polymorphisms in the toxin A and B genes of Clostridium difficile. FEMS Microbiol Lett 148, 197-202.

Rupnik, M., Avesani, V., Janc, M., von Eichel-Streiber, C. \& Delmée, M. (1998). A novel toxinotyping scheme and correlation of toxinotypes with serogroups of Clostridium difficile isolates. J Clin Microbiol 36, 2240-2247.

Sánchez-Hurtado, K. \& Poxton, I. R. (2008). Enhancement of the cytotoxic activity of Clostridium difficile toxin A by surface-associated antigens. J Med Microbiol 57, 739-744.

Sharp, J. \& Poxton, I. R. (1986). Analysis of the membrane lipocarbohydrate antigen of Clostridium difficile by polyacrylamide gel electrophoresis and immunoblotting. FEMS Microbiol Lett 34, 97-100.

Warny, M., Pepin, J., Fang, A., Killgore, G., Thompson, A., Brazier, J., Frost, E. \& McDonald, L. C. (2005). Toxin production by an emerging strain of Clostridium difficile associated with outbreaks of severe disease in North America and Europe. Lancet 366, 1079-1084. 